\title{
Manual de Práctica Sanitaria
}

\author{
Health Practice Manual
}

\section{Presentación}

El Manual fue dirigido y anotado por el Dr. Enrique B. Barnet, Jefe Ejecutivo del Departamento de Sanidad de La Habana y Vocal-Secretario de la Junta Superior de Sanidad. Se indicó en su portada que era "para uso de jefes e inspectores de sanidad, médicos, funcionarios, etc. de la República de Cuba".

Se indica también quienes lo redactaron destacándose entre ellos Arístides Agramonte, Enrique Barnet, Juan Santos Fernández, Carlos J. Finlay, J orge Le Roy y Cassá y Enrique Núñez.

La edición fue de 3000 ejemplares e impresión excelentes. No aparece sello editorial. EI volumen es de 1114 páginas en su cuerpo central, XXII para Prefacio, Introducción y Tabla de materias y XIV para Índice Alfabético de Materias, Membresía de la Junta Superior de Sanidad y Otras Publicaciones relacionar con el tema de la obra.

Se incluyen en el texto numerosas ilustraciones.

\section{PREFACIO}

A la joven República de Cuba cupo la dicha de nacer en los albores de un siglo de luces, en medio de una atmósfera chispeante de descubrimientos científicos y de modo que sus primeros alientos hayan sido de progreso hayan sido de nobles aspiraciones. De ahí que Cuba, depositando sus destinos en manos dignas, amaestradas en la dura escuela de la adversidad y de la lucha, discípula ayer, aspire hoy, en su modesta esfera, a ser cuasi émula de su potente y archimillonaria vecina del norte, al procurar que se cumpla la prescripción que encierra la divisa que ostentamos en el escudo de nuestro Departamento: 
Al inaugurarse la República, apenas tres años ha, cuando se me honró con el nombramiento de Jefe de Sanidad de la isla, intenté excusarme, no sólo por lo que a mi propio respecta, al sentirme incompetente para asumir tan elevada responsabilidad, sino también al encontrarme con la perspectiva de no poder contar, salvo raras excepciones, con el auxilio de un personal que no fuese entonces tan inexperto como yo era en materias de administración sanitaria. Y si al fin cedí ante la insistencia y los razonamientos del generoso é ilustrado Secretario de Gobernación de aquella fecha* debese a que no tuve a bien faltar a un precepto que leí una vez en un cuaderno de enseñanza, modelo de escritura para niños que decía: Never say I can't; say I' II try. "No digas jamás: no puedo; di: trataré de hacerlo."

He debido mi salvación, en tan difíciles momentos -y me complazco en proclamarlo ingenuamente - a la inteligencia, actividad y pericia de otro compañero tan novicio como yo, que fue entonces también designado para J efe Ejecutiva del Departamento de Sanidad de la Habana, y quien hoy tan dignamente ostenta, además los títulos de Vocal Efectivo y de Secretario de la J unta Superior de Sanidad. ¿A qué nombrarlo? El nombre de nuestro querido amigo.

El Dr. Enrique B. Barnet, está grabado en la mente de todos los que se interesan por nuestros asuntos sanitarios. A su luminosa inspiración y á su habilidad en concebir y ordenar el plan de esta obra; deberá el lector y deberá el país la publicación de un MANUAL DE PRACTICA SANITARIA, ajustado a nuestras necesidades locales, quizás único en su clase y cuya utilidad no necesito encarecer.

Indulgencia en sus críticas sólo me resta solicitar del lector, en nombre de todos los que hemos contribuido a la formación de este modesto libro, procurando, con nuestras escasas fuerzas, cumplir airosamente el programa que le fue señalado a cada uno.

\title{
INTRODUCCIÓN
}

\author{
Creer que bastan las buenas leyes sanitarias para \\ mejorar un país, sin una administración técnica bien organizada \\ y siempre vigilante, que tenga los poderes necesarios para \\ hacerlas respetar, es preparar amargas decepciones para el porvenir
}

Bizzozero

Este libro está escrito solamente para los que en Cuba, por razón de sus cargos oficiales ó del ejercicio profesional, estén en el deber de prestar atención asidua a nuestros asuntos de Sanidad. Libro sin pretensión alguna, ni aspira a salir del estrecho círculo a que está destinado, ni mucho menos a traspasar nuestra fronteras. No tiene otro propósito que el de ser de alguna utilidad a aquellos a quienes está dedicado como medio de extender los conocimientos de la moderna ciencia sanitaria. Si la obra llega al 
público o sale de nuestras playas será sólo con motivo de solicitud especial, cortesía mutua o canje establecido. Sería, pues, improcedente que la crítica le fuese adversa, sobre toso cuando no se propone llenar un fin didáctico, sino de propaganda oficial sanitaria entre contados elementos.

Sin suponer que este cumple debidamente tal objeto, hay en Cuna necesidad de un MANUAL, de esta índole. Es de tan reciente data la reforma del concepto antiguo de la Higiene pública, principalmente en los pueblos latinos, que es muy reducido el número de obras que ofrezcan de estas materias fuente abundante de información, principalmente en nuestros idioma. Los descubrimientos científicos de nuestra época, tanto en los que se refiere a la etiología como a la profilaxis de las enfermedades, han cambiado por completo los procedimientos de la Higiene pública. A la bacteriología, a la química, a la historia natural y a las inmortales investigaciones de Jenner, Pasteur, Behring, Kitasato, Yersin, Koch y Finlay, se debe la modificación del punto de vista de la Higiene. La Higiene es hoy la teoría, el conocimiento de los medios de precaver las enfermedades. De aquellos trabajos ha nacido una nueva ciencia: la Sanidad, que viene a ser como la clínica, o la aplicación práctica de aquel conocimiento a la lucha para la prevención de las enfermedades.

Constituida la República, y traspasado poco días después al Gobierno cubano, por el de la Intervención, el Departamento de Sanidad y acabada de promulgar la Orden Militar núm. 159, de 1902, que es aun la ley orgánica de Sanidad que nos rige, ofrecía ésta la ardua tarea de constituir la Junta Superior del Ramo y en todos los municipios las juntas locales. Al cesar la intervención americana, sólo nos dejó en funciones los Departamentos de Sanidad de la Habana, de Santiago de Cuba y de alguna que otra población importante, pero sin un lazo o nexo común que uniese al servicio todo con la uniformidad de acción necesaria.

El Dr. Diego Tamayo y Figueredo, que en aquella fecha era el Secretario de Gobernación, tuvo el buen acierto de elegir para el desempeño de la J efatura Superior de Sanidad, al Dr. Carlos J. Finlay, cuyo bien ganado prestigio en el país y en el extranjero, siendo ya su nombre inmortal la más universal y legitima de las glorias científicas de Cuba, era una base sólida, un garantía para la buena marcha de tan importante Departamento. Y cuando el Dr. Tamayo se proponía disponer la constitución de la Junta Superior y de las J untas locales, ocurrieron los sucesos que tuvieron por consecuencia su lamentable salida del Gabinete. La realización del empeño tócale a su sucesor, Eduardo Yero, ordenó la inmediata organización del servicio de Sanidad en toda la República.

Desde entonces data el proyecto de este libro, y como en aquella fecha, según hemos dicho, no estaba constituida la Junta Superior de Sanidad, fuéle concedida al Departamento de la Habana la autorización para dar término a la obra.

Todos los colaboradores del libro, bien como miembros de la Junta Superior, bien como empleados técnicos, pertenecen a la Sanidad de Cuba. Debido a tan extensa colaboración y, por tanto, a la dificultad de allegar prontamente los originales, así como al fracaso económico de la casa tipográfica que dio principio a la tarea, la publicación ha sufrido una larga demora. Preciso fue cuando el trabajo estaba casi a la mitad, cederlo al

impresor que seguía al primero por turno de mejor precio en la subasta y que ha dado cima a la parte material de la obra de la manera excelente con que aparece.

Así pues, Organizadas ya las juntas locales y funcionando sus Jefes de Sanidad respectivos en todos los municipios de la República, un libro como el presente es útil, a fin de establecer un criterio general, una base común en que sentar el concepto o procedimientos acerca de las enfermedades evitables o transmisibles de declaración obligatoria, la manera de realizar la prevención y la defensa contra las mismas, así como los medios de profilaxis general o de saneamiento de que podemos valernos 
actualmente en Cuba para llenar los fines de la Higiene pública. De ahí la división del libro en dos partes, de conformidad con ese programa.

Entre la lista de enfermedades de declaración obligatoria, la Junta Superior de Sanidad ha acordado incluir algunas solo con el propósito de de ejercer sobre ellas una estricta policía sanitaria; tales son las Oftalmías y la Enteritis de cualquier naturaleza, la Varicela, el Tétanos infantil, la Anquilostomiasis o Uncinariasis, y últimamente, terminado ya el libro, el Dengue, el I ctero grave y las Nefritis agudas en sujetos no inmunes a la Fiebre Amarilla.

Sobre los casos denunciados de estas últimas enfermedades, se práctica un cuidadoso examen por e Departamento de Sanidad, para que no pueda pasar inadvertido por error de diagnóstico, que pudiera ser de lamentables consecuencias para la salud pública, ningún caso de las enfermedades transmisibles que tienen con aquellas cierta analogía, como la Varicela con Viruela. El I ctero grave con la Fiebre Amarilla, o que merezcan alguna investigación especial, como las Enteritis y el Tétanos de los recién nacidos. A veces, por el contrario, la investigación tiene por objeto el evitar que aparezcan en nuestro país casos de enfermedades que no existan realmente sino por una confusión de diagnóstico, como por ejemplo: Viruela o Varioloide por Varicela, Fiebre Amarilla por Dengue y Cólera Asiático por Cólera Nostras.

Esa asidua vigilancia es tanto más importante cuanto que, dice Finlay, la base de toda organización sanitaria destinada á evitar la propagación de enfermedades transmisibles, consiste en las tres condiciones siguientes: $1^{a}$ Tener facultades y personal idóneo para poder estar informado de cualquier caso sospechoso que ocurra á fin de establecer un diagnóstico positivo con todas las garantías necesarias. $2^{\mathrm{a}}$ Tener personal, material de desinfección y medios de transporte adecuados para poder aislar oportunamente al enfermo, desinfectar los locales contaminados y poner guardas para impedir que se expongan al contagio personas susceptibles de contraerlo. $3^{\text {a }}$ Vigilar las vías de comunicación marítimas ó terrestres para precaver que se introduzcan subrepticiamente casos de enfermedades transmisibles ya manifiestos ó en período de incubación, á fin de que no se originen epidemias en la localidad ó se extiendan por todo el país.

Al no cumplirse con todo rigor cualquiera de las tres susodichas condiciones, puede darse por seguro que, en las circunstancias en que se encuentra Cuba por su tráfico constante con países infectados, no habrá protección eficaz para sus habitantes: la Fiebre Amarilla y la Viruela volverán á arraigarse en su suelo y la Peste Bubónica, el Cólera ó el Tifus exantemático se nos entrará en buques procedentes de lugares donde existan estas enfermedades.

Y sin esperar á que tales desgracias se realicen, nuestros vecinos del Norte, al tener noticias de ese desamparo, se apresurarán á establecer cuarentenas para todas las procedencias cubanas, como en los peores tiempos de nuestras relaciones sanitarias internacionales.

Sin tener en cuenta las pérdidas de vidas y el alejamiento de la inmigración que tales trastornos ocasionaran; las trabas y perjuicios materiales que sufrieran el comercio, la industria y demás fuentes de riqueza de la nación, resultarían para el Estado y para nuestros industriales y hombres de negocio muy superiores a las economías que se intentaran realizar para que se dejara de llenar estrictamente, en nuestro servicio sanitario, cualquiera de las tres condiciones fundamentales que dejamos señaladas.

Por su condición geográfica, Cuba, como isla, está favorablemente situada para librarse de las invasiones epidémicas del exterior, mediante una policía de sanidad marítima esmerada. No existe actualmente en nuestro país ni un solo paciente de enfermedad cuarentenable aguda; únicamente se registran casos de una crónica: la lepra. 
El servicio sanitario nacional está conveniente mente preparado para defender al territorio contra la invasión de cualquier enfermedad exótica; pero preciso es confesar que no lo esta aun para obtener el saneamiento perfecto del país y hacerlo refractario a la aparición y propagación de enfermedades transmisibles. Todas las atenciones de carácter sanitario de la República, debieran ser sufragadas por el Estado. Para nosotros el problema sanitario tiene dos aspectos: uno el compromiso internacional consignado en el apéndice de nuestra Constitución; otro el de utilidad propia, por la salud y la vida de los habitantes del país y por la atracción de la corriente emigratoria que ha de aumentar nuestra población y acrecentar nuestra riqueza.

Al Estado y no a los Ayuntamientos toca la responsabilidad de las condiciones sanitarias de Cuba. Con excepción de la Habana y de los términos municipales que la circundan, el servicio de sanidad está sostenido por los Ayuntamientos con consignaciones verdaderamente mezquinas en sus presupuestos y aprovechando, so pretexto de una incompatible y contraproducente economía, a los médicos municipales y forenses para el desempeño gratuito de las Jefaturas locales de Sanidad. A los miembros de las Juntas locales, si perciben algún sueldo del Estado, la Provincia o el Municipio, no se les abona la remuneración a que tienen derecho por la Orden 159, y bien sabido es que resultado tiene, por lo general, todo cargo público no retribuido que exija tiempo y labor. Los Ayuntamientos se encuentran de este modo sin recursos de ningún género para hacer desaparecer las causas de insalubridad, no solamente de los lugares públicos, sino de las propiedades privadas y, salvo contadas excepciones, permanecen indiferentes y hasta hostiles a las exigencias de la higiene.

Es preciso obligar a estos Ayuntamientos a que realicen en pro de la Sanidad municipal los sacrificios que esta demanda. A fin de que no constituyan un peligro para sus propios vecinos y para todo el país, y que no quede la salubridad pública a la merced exclusiva de las buenas voluntades colectivas o individuales. Todo cuanto se emplee en atenciones sanitarias, es caudal colocando con buena garantía en la caja de ahorros de la Higiene pública. Una vida salvada, cuando ha podido lograrse, es un capital ganado en el activo de una raza o de un pueblo, y de acuerdo con Muñiz podemos afirmar que nada acredita tanto el grado de civilización de un país como sus instituciones sanitarias.

Hace, pues falta, una ley de Sanidad. Una ley que le dé unidad al servicio, que establezca que sea éste sufragado por el Estado, que le dé todo la fuerza indispensable a las autoridades sanitarias para que puedan tener en sus manos la defensa contra los ataques a la salud pública y hacer refractario el suelo de Cuba a la propagación de las enfermedades pestilenciales; ley que atienda en primer término a los principios esenciales de la Higiene que son: la cualidad y cantidad del agua, la pureza de los alimentos, la construcción de cloacas, la salubridad de las habitaciones, las vacunaciones preventivas y curativas, la policía marítima, el aislamiento de los enfermos y la desinfección de los locales y de los objetos contaminados. De este modo se llegará a disminuir la morbilidad y la mortalidad en una proporción relativamente considerable y así se respetará y conservará el capital humano, que es, como ha dicho Cornil, la más preciosa de las riquezas nacionales.

Al dictarse la proyectada Ley de Sanidad, deben tener presentes nuestros legisladores las siguientes palabras de Palmberg:

"Más que ninguna otras, las leyes sanitarias atacan a la libertad individual, porque para ser eficaces deben restringir necesariamente la inviolabilidad del domicilio. Para asegurarse de que se observan es preciso, en efecto, visitar las casas y patios, hacer desinfectar las habitaciones, etc. Ahora bien, en ninguna parte se halla tan arraigada la idea de la libertad individual y de la inviolabilidad del domicilio como entre los ingleses. Poseen la Constitución del Habeas corpus, y el proverbio my house is my castle (mi casa es mi castillo) enseña con harta claridad la opinión que todo inglés tiene de sus derechos. Esto no impide que se someta con solicitud a leyes que le quitan una buena parte de esta libertad. La razón es que para un inglés la voz libertad no es una palabra 
vana, sino que, por el contrario, designa todo lo que puede garantizar al individuo y librarse de los inconvenientes y peligros inherentes a la vida en sociedad.

El inglés tenía ya sus instituciones de policía para defenderse contra la violencia de otro y en cuanto reconoció la posibilidad de prevenir una gran número de enfermedades, se dio conducido por la fuerza de la lógica a exigir que el Estado tomara también medidas capaces de preservarle de ellas.

Y como el único medio de alcanzar este resultado es la puntual ejecución de tales medidas no solamente se conforma con ellas por su parte, sino que vigila con el mayor cuidado por que los demás se sometan del mismo modo".

En breve plazo serán promulgadas las Ordenanzas Sanitarias que ha redactado la Junta Superior de Sanidad y sometido a la aprobación del Ejecutivo para el régimen de los Ayuntamientos de la República. Estas Ordenanzas podrán tenerse en cuenta para la formación de la nueva ley a la cual podrán después ser adaptadas con ligeras modificaciones, supuesto que comprenden casi todos los asuntos propios de los reglamentes sanitarios.

Para la aplicación de estas Ordenanzas se habrá de tropezar, sin duda, con innúmeros obstáculos. Como a casi todas las reformas sanitarias, le habrán de salir al encuentro el prejuicio y la ignorancia de muchas gentes, el egoísmo personal de los lesionados y la oposición sistemática de una jerarquía de autoridades, y se esforzarán todos por entorpecer el cumplimiento de las disposiciones, si no se cuenta con un apoyo fuerte en el gobierno superior donde se asiente firmemente el concepto del deber sanitario para que se respeten y cumplan aquellas disposiciones, en contra de la resistencia de los intereses privados, que se manifiesta siempre tenaz en frente de los intereses generales.

Como estableció Berthelot, cuando se le oponían objeciones a la ley francesa porque exigía el conocimiento previo por las autoridades sanitarias de los planos de las casa en construcción y la necesidad de edificar habitaciones salubres, -hay ciertas enfermedades que no dependen del régimen individual, sino que son afecciones epidémicas y contagiosas por excelencia y se desarrollan mediante la insalubridad, la suciedad, la ignorancia, la falta de cuidados de los habitantes, la distribución peligrosa de las aguas y los defectos de construcción de las habitaciones. Las medidas sanitarias afectan, por lo general, en primer términos a las clases proletarias, esto es, a los que por consecuencia de su condición se encuentra comúnmente en situación económica desfavorable. Es natural que así suceda, puesto que los ricos pueden vivir rodeados de las mejores condiciones higiénicas. Los pobres son, por tanto, a los que en primer lugar se favorecen con las disposiciones sanitarias, ya que a ellos no les es posible defenderse por sí mismos. Las exigencias de la Higiene pública no son, pues medidas de opresión, sino medidas de protección a favor de la vida y la salud de los débiles y necesitados.

"Cuando se creía que la insalubridad de un alojamiento no era perjudicial sino para su propietario o los que lo habitaban, era natural el permitirles libertades que no podían hacer daño sino a sí propios. Pero la ciencia ha progresado y ha demostrado con seguridad y precisión crecientes, las leyes de la solidaridad sanitaria. Sábese que las enfermedades infecciosas tienen, como agentes de transmisión y de propagación, elementos específicos, que toda insalubridad es como un nido en que prosperan o se multiplican y desde donde se diseminan los contagios específicos de estas enfermedades; que los vecinos se ven amenazados y atacados por ellas, y que la infección, avanzando de lugar, en lugar hace que se vea en peligro todo el territorio por la insalubridad de cualquiera de sus partes."

Desde entonces, ha cambiado el aspecto de las cosas o, mejor dicho, se ha ensanchado el punto de vista. Lo que podía ser tolerable cuando se le creía inofensivo, no puede ya serlo desde que se le considera nocivo. Así es que cuando con respecto a un individuo 
enfermo, una casa insalubre, una localidad malsana, se dictan las medidas que la ciencia ha establecido o que la experiencia ha comprobado su eficacia, no es el individuo, ni a la casa, ni a la localidad a los que se defiende contra ellos mismos, sino que es a los vecinos, al territorio y a todos nosotros a los que protegemos contra ellos.

Esto es una aplicación nueva de un principio viejo como las sociedades, a saber que nadie tiene el derecho de perjudicar a otro. Desde este punto de vista nuevo, resultado del progreso de la ciencia, se percibe la legitimidad o la necesidad de la intervención de la ley en las cuestiones de Higiene pública. Como consecuencia de esto, muchas naciones civilizadas se han apresurado de pocos años acá, a dictar leyes sanitarias nuevas, inspiradas no sólo en un sentimiento de humanidad y deber, sino también en la idea económica de que nada hay tan costoso para una nación como la enfermedad y la muerte. Aunque diferentes en sus procedimientos, todas estas legislaciones tiene por carácter común el confiar las medidas sanitarias a manos de personas competentes, es decir, científicamente competentes, y han dado por resultado invariable la disminución de la mortalidad, especialmente por enfermedades contagiosas.

No existe con ello ningún ataque al ejercicio legítimo de la libertad. En una época en que se ignoraba lo que se sabe hoy, podía reclamarse para el propietario lo que se llamaba ingeniosamente "la triste libertad del suicidio"; más al presente nadie reclamaría para ese propietario la culpable libertad del envenenamiento. Todo el mundo, por el contrario, reivindicaría a favor de la gran masa de ciudadanos la libertad, infinitamente más respetable, de no ser envenenados.

En defensa de la libertad de todos la ley prohibe al propietario que le prenda fuego a su propia casa, que tenga en ella gran cantidad de materias explosivas, o que construya tan elevado el edificio que intercepte el aire y la luz a sus vecinos. En virtud de este mismo principio, no es permitido el derecho de crear o de conservar en una casa cualquier causa permanente de insalubridad, porque existiendo ésta no es sólo al dueño o a los habitantes de aquella a quienes se perjudica, sino que también a los otros, a los vecinos a quienes se daña y al impedir todo esto no se viola la libertad sino que se le protege. Nadie tiene derecho de poseer una habitación insalubre, porque la salubridad de una propiedad es una carga natural de la misma. Esta es una aplicación del admirable principio general del gran jurisconsulto francés Domat: "El orden que une a los hombres a no perjudicarse por si mismos, sino a tener también todo cuanto posean en un estado tal que nadie reciba de ellos daño ni perjuicio".

Esos conceptos de Rochard son los que deben guiar en sus deliberaciones a los encargados de confeccionar las leyes y reglamentos de Sanidad y a los funcionarios llamados a hacerlos cumplir, para que resulten eficaces y se sostenga incólume el lema de "Salus populi suprema lex".

Séanos permitido consignar en este sitio en, nombre del Departamento de Sanidad, un tributo de gratitud para el Jefe de Estado, para el Consejo de Secretarios, y especialmente para la Secretaría de Gobernación, por sus auxilios eficaces para llevar a término la impresión de este libro.

Y al cerrar este trabajo, dediquemos un recuerdo de afecto y veneración a la memoria de nuestro ilustre colaborador, el Dr. Julio San Martín, miembro de la Junta Superior de Sanidad, caído en el rudo batallar de la vida antes de que pudiese ver impreso el notabilísimo Capitulo que lleva su firma en este MANUAL. ¡Duerma en paz el amigo amado, que tanto trabajo por la ciencia y la cultura de la patria! 


\begin{tabular}{|l|l|l|}
\hline \multicolumn{2}{|c|}{ TABLA DE MATERI AS } \\
\hline \multicolumn{2}{|c|}{} & Págs \\
\hline I. & $\begin{array}{l}\text { Prefacio } \\
\text { Dr. Carlos J. Finlay }\end{array}$ & I I I \\
\hline \begin{tabular}{|l|l|}
\hline Introducción \\
II. Enrique B. \\
Barnet
\end{tabular} \\
\hline
\end{tabular}

\begin{tabular}{|c|c|c|}
\hline \multicolumn{3}{|c|}{ PRI MERA PARTE } \\
\hline \multicolumn{3}{|c|}{ ENFERMEDADED DE DECLARACIÓN OBLIGATORIA } \\
\hline III & $\begin{array}{l}\text { Fiebre amarilla. Fiebre de Borras } \\
\text { Dr. Carlos J. Finlay }\end{array}$ & 1 \\
\hline IV & $\begin{array}{l}\text { Paludismo. Fiebre de Malta } \\
\text { Dr. Juan Guiteras }\end{array}$ & 21 \\
\hline V & $\begin{array}{l}\text { Tuberculosis } \\
\text { Dr. Joaquín L. Jacobsen }\end{array}$ & 47 \\
\hline VI & $\begin{array}{l}\text { Fiebre tifoidea } \\
\text { Dr. Antonio Díaz Albertini }\end{array}$ & 85 \\
\hline VII & $\begin{array}{l}\text { Difteria., Parotidis epidémica } \\
\text { J osé A. Clark }\end{array}$ & 101 \\
\hline VIII & $\begin{array}{l}\text { Fiebre infecciosa. Tifus exantemático } \\
\text { Dr. José Villa Davin }\end{array}$ & 147 \\
\hline IX & Fiebres eruptivasDr. Arístides Agramonte & 163 \\
\hline$x$ & $\begin{array}{l}\text { Oftalmias } \\
\text { Dr. Juan Santos Fernández }\end{array}$ & 179 \\
\hline$X I$ & $\begin{array}{l}\text { Enteritis. Tiñas } \\
\text { Dr. J oaquín L.. Dueñas }\end{array}$ & 241 \\
\hline XII & $\begin{array}{l}\text { Tétanos infantil. Tos ferina. Septicemia } \\
\text { puerperal } \\
\text { Dr. Gonzalo Aróstegui }\end{array}$ & 301 \\
\hline XIII & $\begin{array}{l}\text { Gripe. Neumonía. Meningitis cerebro-espinal } \\
\text { epidémica } \\
\text { Dr. Ernesto de Aragón }\end{array}$ & 347 \\
\hline XIV & $\begin{array}{l}\text { Disentería epidémica. Erisipela. Beri-Beri } \\
\text { Dr. Eugenio Albo y Cabrera }\end{array}$ & 369 \\
\hline $\mathrm{XV}$ & $\begin{array}{l}\text { Muermo y Farcino. Rabia. Actinomicosis. Antrax } \\
\text { Dr. Juan N. Dávalos }\end{array}$ & 401 \\
\hline $\mathrm{XVI}$ & $\begin{array}{l}\text { Sífilis. Blenorragia. Lepra } \\
\text { Dr. José Varela Zequeira }\end{array}$ & 431 \\
\hline XVII & $\begin{array}{l}\text { Cólera asiático. Cólera nostras. Peste Bubónica } \\
\text { Dr. Enrique B. Barnet }\end{array}$ & 495 \\
\hline XVIII & FilariasisDr. Federico Torralbas & 553 \\
\hline
\end{tabular}




\begin{tabular}{|l|l|l|}
\hline XIX & Epizootias. EnzootiasDr. Julio San Martín & 558 \\
\hline XX & $\begin{array}{l}\text { Anquilostomiasis o Uncinariasis } \\
\text { Dr. Mario G. Lebredo }\end{array}$ & 631 \\
\hline & $\begin{array}{l}\text { Técnica de la recolección de muestras } \\
\text { patológicas que han de enviarse al laboratorio } \\
\text { para fijar el diagnóstico } \\
\text { Dr. Emilio Martínez }\end{array}$ & 651 \\
\hline XXII & $\begin{array}{l}\text { Cuadro sinóptico de la incubación, etiología y } \\
\text { profilaxis de las enfermedades transmisibles } \\
\text { Dres. A. Diedonne y Juan Guiteras }\end{array}$ & $664 a$ \\
\hline
\end{tabular}

\begin{tabular}{|c|c|c|}
\hline \multicolumn{3}{|c|}{ SEGUNDA PARTE } \\
\hline \multicolumn{3}{|c|}{ PROFILAXIS GENERAL Y SANEAMI ENTO } \\
\hline XXIII & $\begin{array}{l}\text { El Departamento de Sanidad de la Habana. } \\
\text { Su organización, procedimiento y marcha } \\
\text { Dr. J osé A. López del Valle }\end{array}$ & 667 \\
\hline XXIV & $\begin{array}{l}\text { I ngeniería sanitaria } \\
\text { Sr. Cristino Figuerola Cowan }\end{array}$ & 754 \\
\hline$x x V$ & $\begin{array}{l}\text { Los Mosquitos de Cuba } \\
\text { Dr. Mario G. Lebredo }\end{array}$ & 784 \\
\hline XXVI & La Vacuna Dr. Vicente de la Guardia & 818 \\
\hline XXVII & $\begin{array}{l}\text { Casa de vecindad. Dispensario especial } \\
\text { Dr. Juan B. Fuentes }\end{array}$ & 839 \\
\hline XXVIII & $\begin{array}{l}\text { Posadas. Cafés. Restaurants. Teatros. } \\
\text { Mercados. Fábricas de tabacos. Establos } \\
\text { Dr. Manuel Martínez Avalos }\end{array}$ & 858 \\
\hline$X X I X$ & $\begin{array}{l}\text { Hospitales. Asilos- Cárceles. Presidios } \\
\text { Dr. Narciso G. Casas }\end{array}$ & 875 \\
\hline$x X X$ & $\begin{array}{l}\text { Higiene de las escuelas } \\
\text { Dr. Gustavo G. Duplessis }\end{array}$ & \\
\hline XXXI & $\begin{array}{l}\text { Establecimientos insalubres, peligrosos e } \\
\text { incómodos } \\
\text { Dr. Jorge A. Ponce }\end{array}$ & 913 \\
\hline XXXII & $\begin{array}{l}\text { Vehículos públicos } \\
\text { Dr. José Urzals }\end{array}$ & 930 \\
\hline XXXIII & $\begin{array}{l}\text { Aguas potables. Acueductos } \\
\text { Dr. Ambrosio Grillo }\end{array}$ & 942 \\
\hline XXXIV & $\begin{array}{l}\text { Desinfección. Desinfectantes } \\
\text { Dr. Enrique Nuñez }\end{array}$ & 963 \\
\hline$X X X V$ & $\begin{array}{l}\text { Ensayos químicos de algunas substancias } \\
\text { alimenticias: Procedimientos prácticos y } \\
\text { rápidos } \\
\text { Dr. Emilio Pardiñas }\end{array}$ & 980 \\
\hline $\mathrm{XXXVI}$ & $\begin{array}{l}\text { Estadísticas demográfica } \\
\text { Dr. Jorge Le Roy }\end{array}$ & 993 \\
\hline XXXVII & $\begin{array}{l}\text { EI Departamento de cuarentenas. Su } \\
\text { organización, procedimientos y marcha } \\
\text { Dr. Hugo Robert }\end{array}$ & 1015 \\
\hline
\end{tabular}




\begin{tabular}{|l|l|l|}
\hline XXXVIII & $\begin{array}{l}\text { El Departamento de inmigración. Su } \\
\text { organización, procedimientos y marcha } \\
\text { Dr. Frank E. Menocal }\end{array}$ & 1052 \\
\hline XXXIX & $\begin{array}{l}\text { El Laboratorio de la Isla de Cuba } \\
\text { Dr. Manuel Masforroll }\end{array}$ & 1074 \\
\hline XL & $\begin{array}{l}\text { El Hospital "Las Animas" } \\
\text { Dr. Enrique B. Barnet }\end{array}$ & 1090 \\
\hline XLI & $\begin{array}{l}\text { Legislación sanitaria } \\
\text { Dr. José A. del Cueto }\end{array}$ & 1106 \\
\hline
\end{tabular}

${ }^{*}$ El Dr. Diego Tamayo y Figueredo. 